\title{
Analysis of Imazaquin in Soybeans by Solid-phase Extraction and High-performance Liquid Chromatography
}

\author{
C. Guo $\cdot$ J. -Y. Hu $\cdot$ X. -Y. Chen $\cdot$ J. -Z. Li
}

Received: 1 November 2007/ Accepted: 10 December 2007/Published online: 9 January 2008

(C) Springer Science+Business Media, LLC 2008

\begin{abstract}
An analytical method for the determination imazaquin residues in soybeans was developed. The developed liquid/liquid partition and strong anion exchange solid-phase extraction procedures provide the effective cleanup, removing the greatest number of sample matrix interferences. By optimizing mobile-phase $\mathrm{pH}$ water/acetonitrile conditions with phosphoric acid, using a C-18 reverse-phase chromatographic column and employing ultraviolet detection, excellent peak resolution was achieved. The combined cleanup and chromatographic method steps reported herein were sensitive and reliable for determining the imazaquin residues in soybean samples. This method is characterized by recovery $>88.4 \%$, precision $<6.7 \% \mathrm{CV}$, and sensitivity of $0.005 \mathrm{ppm}$, in agreement with directives for method validation in residue analysis. Imazaquin residues in soybeans were further confirmed by high performance liquid chromatographymass spectrometry (LC-MS). The proposed method was successfully applied to the analysis of imazaquin residues in soybean samples grown in an experimental field after treatments of imazaquin formulation.
\end{abstract}

Keywords Imazaquin - Residue analysis - Soybeans · SAX-SPE · HPLC-UV

Imazaquin[2-(4-isopropyl-4-methyl-5-oxo-4,5-dihydroimidazol-1H-2-yl]-3-quinoline-3-carboxylic acid] is devel-

C. Guo · J.-Y. Hu ( $\varangle) \cdot$ X.-Y. Chen · J.-Z. Li

Research Center for Eco-Environmental Sciences,

Chinese Academy of Sciences, Beijing 100085,

People's Republic of China

e-mail: hujiye@rcees.ac.cn oped by the American Cyanamid Company (Fig. 1 illustrates the chemical structure of imazaquin).

It is an important member of imidazolinones class, which have an excellent activity against annual and perennial grasses and broad-leafed weeds when applied either pre- or post-emergence (Ahrens 1994). They function by inhibiting acetohydroxy acid synthase, the feedback enzyme in the biosynthesis of branched chain essential acids (Anisuzzaman et al. 2000). Imazaquin was registered in China in 1997 and has been widely used in agriculture, especially in northeast to control soybeans (Wang et al. 2007).

Numerous methods have been reported for determination of imazaquin or a group of imidazolinone herbicides in soil samples, concerning liquid chromatography with ultraviolet detection or liquid chromatography/electrospray mass spectroscopy (LC-UV or LC-MS) (Chen et al. 2007; Lanana et al. 1998), enzyme-linked immunosorbent assay (Steinheimer et al. 1998), capillary electrophoresis (CE) (Nejad et al. 1998) and gas chromatography/electron capture negative ionization mass (GC/MS) (Stout et al. 1996). But methods for residue analysis of imazazquin in soybeans are scare in the scientific literature. Analysis of soybeans is difficult due to its complex composition and, particularly, the presence of oils, waxes and pigments. Nemoto and Lehotay (1998) analysis imazaquin in soybeans using pressurized liquid extraction and $\mathrm{CE}$, and Anisuzzaman et al. determine imidazolinone herbicides by GC-NPD after the derivatization reaction (Anisuzzaman et al. 2000). The disadvantages of the two methods were concerning laborious procedure and complex equipment, and not suitable for routine monitoring in a common analysis laboratory.

This paper presents a rapid and sensitive method for quantification of imazaquin residues in soybeans based 


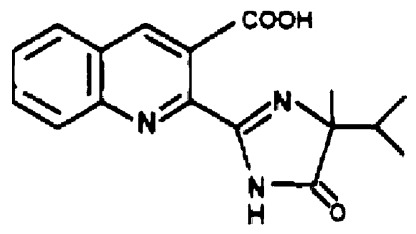

Fig. 1 Chemical structure of imazaquin

on liquid-liquid partition combined with strong anion exchange solid-phase extraction (SAX-SPE) procedure and subsequent determination by HPLC-UV. The proposed method was successfully employed for the determination imazaquin residues levels in soybeans grown in an experimental field after treatments of imazaquin formulation.

\section{Materials and Methods}

Imazaquin (purity, 99.0\%) and its commercial formulation (5\% aqueous solution, AS) were provided by Shenyang Research Institute of Chemical Industry (China). HPLC grade acetonitrile was purchased from Dikma Limited (China). Other solvents and chemicals used were of Analytical Grade from Dikma Limited (China). HPLC grade water was produced using a Milli-Q water purification system (Millipore Co. Milford, MA, USA). SPE columns were Varian Sample Preparation Products (SAX, $500 \mathrm{mg}$ ).

High performance liquid chromatograph (Agilent 1100) equipped with an analytical column $(250 \mathrm{~mm} \times 4.6 \mathrm{~mm}$ I.D., $5 \mu \mathrm{m}$ ODS) attached to a UV detector. The chromatographic conditions used for the analysis of imazaquin residues were as follows: The mobile phase was acetonitrile-water (adjusted to $\mathrm{pH} 2.7$ with phosphoric acid) $(45+55, \mathrm{v} / \mathrm{v})$ with a total flow of $1 \mathrm{~mL} / \mathrm{min}$. The injection volume was $20 \mu \mathrm{L}$; Detection was performed at $240 \mathrm{~nm}$. Under these conditions the retention time of imazaquin was about $7.5 \mathrm{~min}$.

LC-MSD-Trap-VL of Agilent 1100 was applied under the following conditions: Mass Range Mode, Std/Normal; Ion Source Type, ESI; Ion Polarity, Positive; Nebulizer Gas (set), 50.00 psi; Dry Gas (set), 10 L/min. Dry temperature (set), $325^{\circ} \mathrm{C}$; Compound Stability (set), $10 \%$; Auto $\mathrm{MS}^{2}$; Fragment Voltage, 1.0 V; Smart Fragment Mode, 30\%200\%; Scan Range, 100-500 m/z. The analytical column was a $\mathrm{C}_{18}$ column $(150 \mathrm{~mm} \times 4.6 \mathrm{~mm}$ I.D. with a particle size of $5 \mu \mathrm{m}$ ) and other chromatographic conditions were the same as HPLC analysis.

Standard solution $(1,000 \mathrm{mg} / \mathrm{L})$ of imazaquin were prepared in methanol-water $(50+50, \mathrm{v} / \mathrm{v})$ and the solutions required for preparing a standard curve $(0.03,0.1,0.3$, 1,3 , and $10 \mu \mathrm{g} / \mathrm{L}$ ) were prepared from the stock solution by serial dilutions. All solutions were protected against light with aluminum foil and were stored in a refrigerator at $4^{\circ} \mathrm{C}$

Ground soybeans sample ( $20 \mathrm{~g})$ were weighed in a 250 $\mathrm{mL}$ polypropylene container; methanol $(50 \mathrm{~mL})$ and concentrated phosphoric acid $(0.5 \mathrm{~mL})$ were added. The mixture was vigorously shaken for $40 \mathrm{~min}$, and filtered through a $12-\mathrm{cm}$ Büchner funnel; the solid residues was treated with an additional methanol $(30 \mathrm{~mL})$. The combined filtrate was transferred to a flask, evaporated at $40^{\circ} \mathrm{C}$ to dryness on the rotary evaporator, and then distilled water ( $50 \mathrm{~mL}, \mathrm{pH} 12$ adjusted with $0.1 \mathrm{~N} \mathrm{NaOH}$ ) was added. This aqueous mixture was transferred to a $500-\mathrm{mL}$ separatory funnel, add $50 \mathrm{~mL}$ dichloromethane, and shake vigorously for $1 \mathrm{~min}$; transfer the aqueous layer to another separatory funnel, adjust the AS $\mathrm{pH}$ to 1 with phosphoric acid, and add $40 \mathrm{~mL}$ dichloromethane, and shake for $1 \mathrm{~min}$; wash the aqueous layer with another $40 \mathrm{~mL}$ dichloromethane and discard the aqueous layer; filter all the organic portions through anhydrous sodium sulfate and evaporate to dryness at $40^{\circ} \mathrm{C}$, and dilute to exactly $10 \mathrm{~mL}$ with aqueous $\mathrm{NaOH}(\mathrm{pH} 8)$.

Purification procedure was performed on an SAX cartridge. The SAX cartridge was preconditioned with $5 \mathrm{~mL}$ of methanol followed by $5 \mathrm{~mL}$ of distilled water. Sixmilliliter residue obtained above was directly loaded onto the cartridge and the effluent was discarded. The cartridge was rinsed with $2 \mathrm{~mL}$ methanol and the rinsing was also discarded. The analyte was eluted with $12 \mathrm{~mL}$ methanol and then evaporated under vacuum with a rotary evaporator at $45^{\circ} \mathrm{C}$ to dryness. The residue was re-constituted in $2 \mathrm{~mL}$ methanol-water $(50+50, \mathrm{v} / \mathrm{v})$ and then filtered through a $0.45 \mu \mathrm{m}$ filter before HPLC analysis.

Untreated soybean samples $(20 \mathrm{~g})$ were fortified with known amounts of imazaquin (0.005, 0.05, and $0.5 \mathrm{ppm})$ and processed according to the above procedure. Every recovery was done on five replicates.

Field trials were carried out in an experimental farmland located at Xisanqi district of Beijing, China. The area of the field was $300 \mathrm{~m}^{2}$. A random block scheme was used, with three replications for each test, and each block contained $30 \mathrm{~m}^{2}$. The control plots were localized, tagged and separated by guard rows to avoid contamination by drift, etc. Green soybean plants, receiving routine horticultural treatment, were sprayed with imazaquin 5\% AS at two recommended dosages (112.5 and $150 \mathrm{~g}$ of active ingredient per hectare, set by the manufactory of China) on May 15,2006 , using a portable motor sprayer. Soybean samples were collected at harvest time. Immediately after picked, the samples were put into polyethylene bags and transported to the laboratory where they were chopped, thoroughly mixed, and divided into three sub-samples each. The sub-samples were kept deep-frozen $\left(-30^{\circ} \mathrm{C}\right)$ until analysis. 


\section{Results and Discussion}

Standard calibration curve of imazaquin was constructed by plotting analyte concentration against peak areas. At $240 \mathrm{~nm}$, the calibration range was liner from $0.03-10 \mu \mathrm{g} /$ $\mathrm{mL}(r=0.9998$, at least). The standard curve equation was $y=148.5 x+2.773$.

Table 1 shows the pesticide recovery results. The soybean sample was fortified at $0.005,0.05$, and $0.5 \mathrm{ppm}$ before extraction by adding the appropriate volume working standard solution. The recoveries obtained were in the acceptable range of $88.4 \%-96.6 \%$. Figure 2 shows the chromatograms of the imazaquin standard, fortified samples.

The coefficient variation of the methods (CV\%) for repeatability was ranging from $3.1 \%$ to $6.7 \%$. The limit of detection was estimated to be $0.4 \mathrm{ng}$ of the pesticide, based on signal to noise ratio $3: 1$. The limit of quantification (LOQ) for this method was defined as the lowest concentration of compounds in a sample that could be quantitatively determined with suitable precision and accuracy. LOQ of imazaquin was found to be $0.005 \mathrm{ppm}$.

Imazaquin is an amphoteric molecule and should be expected to exist in an ionic state over a wide $\mathrm{pH}$ rang. As such, a complex set of equilibria can govern its physiochemical behavior and affect matrix extraction efficiency and chromatographic separation. In this work, the pesticide was extracted from the sample with acidic methanol due to the acidic nature of the analyte, cleanup by organic/aqueous liquid/liquid partition at different $\mathrm{pH}$ values $(\mathrm{pH} 1$ or 10) combined with SAX SAX-SPE column. A series of liquid/liquid partitions between organic solvents and acid/ base solution was found to be a reasonable alternative for cleaning up fats and other products from aqueous matrix. These partitions followed by SAX-SPE analyte isolation/ elution, eliminated most interfering peaks and allowed good recoveries at low fortification levels.

We initially chose C-18 (octadecylsilyl), primary secondary amine (PSA), strong cation exchange (SCX) and SAX after liquid/liquid partitioning procedures. The extraction yields obtained using PSA cartridges were rather low $(<60 \%)$, while C-18 cartridges gave rise to heavy interference in the chromatogram. As for SCX, the complex ionic behavior of imazaquin made it difficult to select

Table 1 The recoveries of imazaquin in soybeans $(n=5)$

\begin{tabular}{lllllllll}
\hline $\begin{array}{l}\text { Fortified concentration } \\
(\mathrm{ppm})\end{array}$ & \multicolumn{9}{l}{ Recoveries $(\%)$} & & \multirow{2}{*}{$\%$} \\
\cline { 2 - 7 } & 1 & 2 & 3 & 4 & 5 & Average & \\
\hline 0.005 & 97.5 & 95.6 & 96.3 & 100.9 & 92.7 & 96.6 & 3.1 \\
0.05 & 91.8 & 93.2 & 87.4 & 90.5 & 81.7 & 88.9 & 5.1 \\
0.5 & 93.3 & 95.1 & 82.3 & 82.7 & 88.6 & 88.4 & 6.7 \\
\hline
\end{tabular}
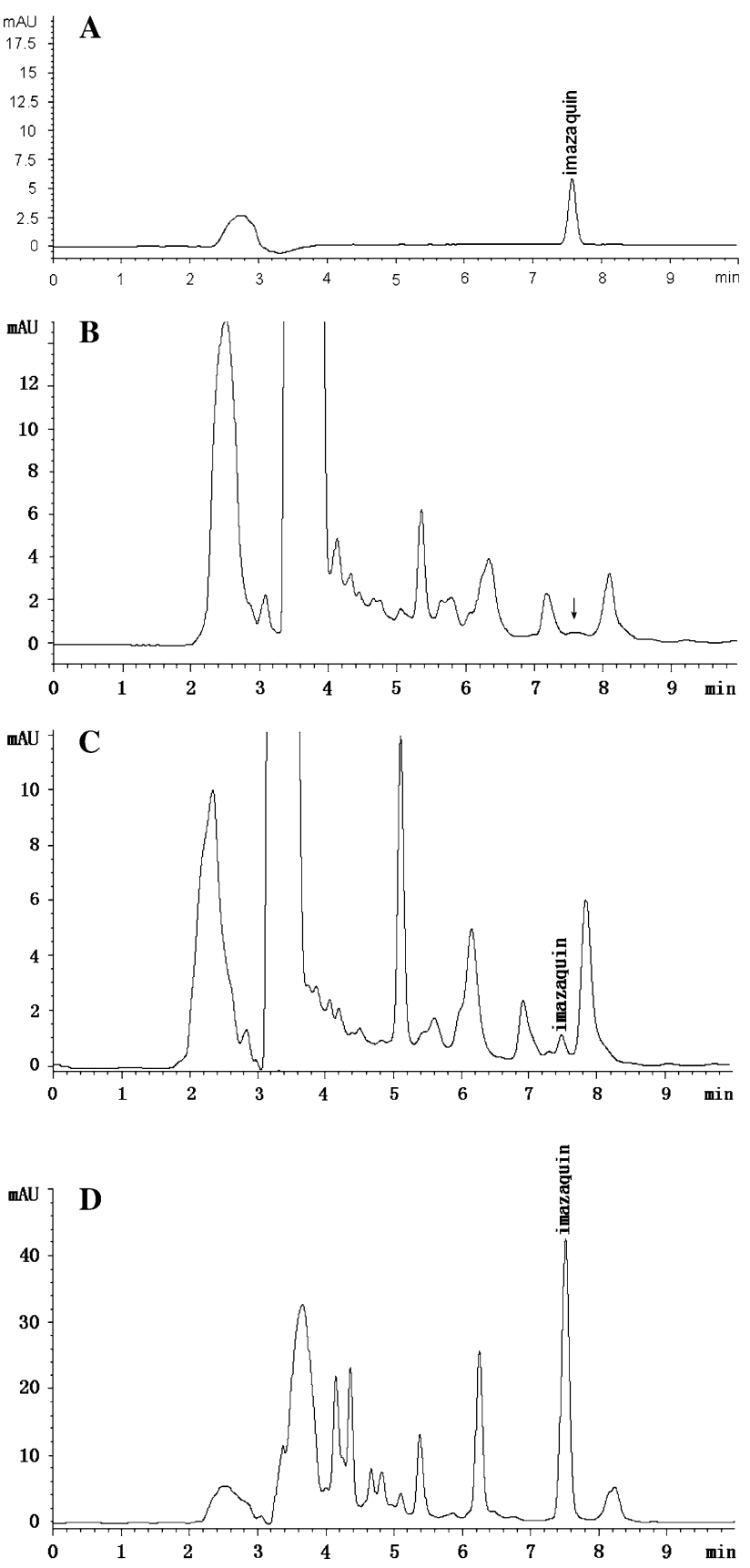

Fig. 2 Chromatogram of (A) imazaquin standard (retention time $\approx$ $7.5 \mathrm{~min}$ ), (B) control soybeans sample, (C) spiked soybeans sample at $0.005 \mathrm{mg} / \mathrm{kg}$, (D) spiked soybeans sample at $0.5 \mathrm{mg} / \mathrm{kg}$

an appropriate elution solvent for consistent and quantitative extraction from the ion-exchange resin bed. Best results were obtained using SAX cartridges, which were this chosen for all subsequent assays. SAX cartridge was also selected in soil sample purification in our previous work (Chen et al. 2007).

All the steps of loading, washing, and elution were carefully examined. Several kinds of loading step were tested: different buffers in the $2.0-8.0 \mathrm{pH}$ range and, 
Fig. 3 LC-MS and LC-MS-MS spectrum imazaquin

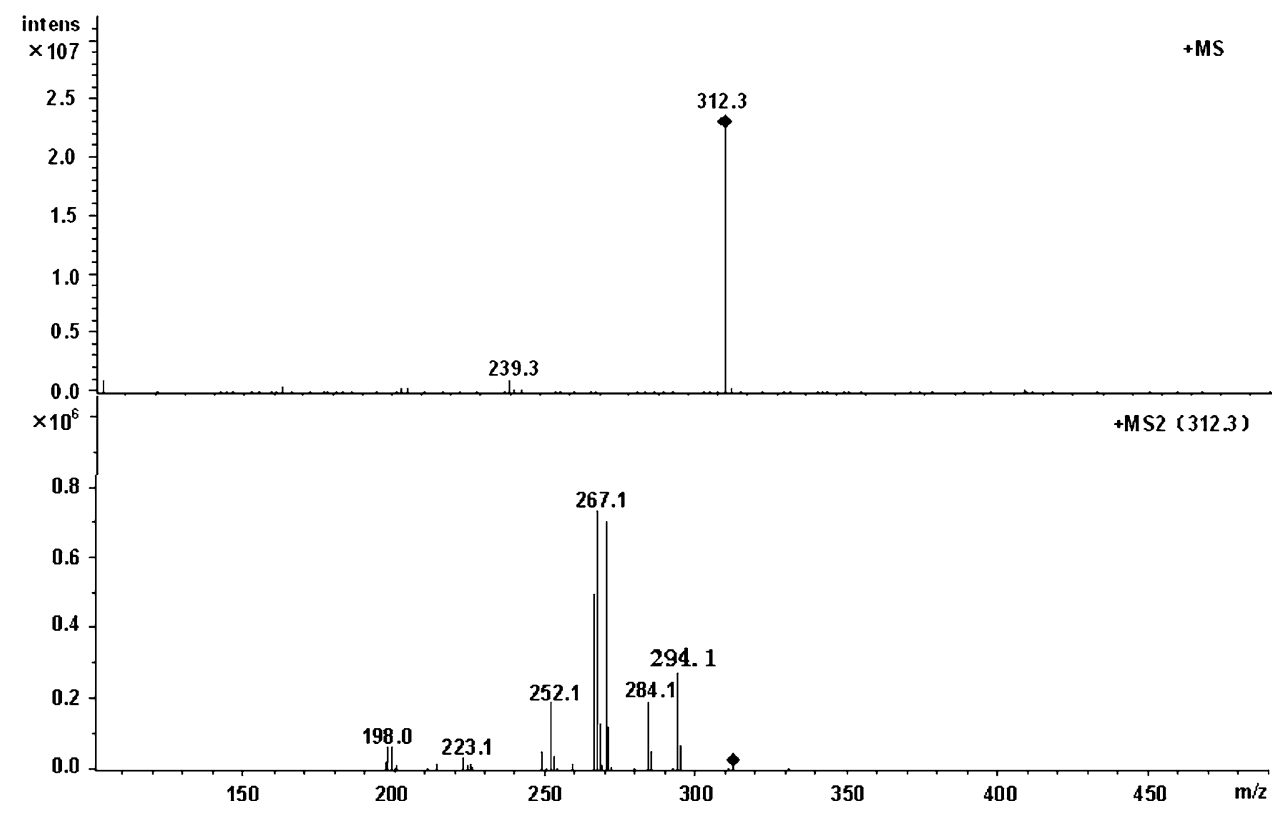

finally, aqueous $\mathrm{NaOH}(\mathrm{pH}=8)$, which turned out to be the best choice. The optimum loading condition was $6 \mathrm{~mL}$ aqueous $\mathrm{NaOH}(\mathrm{pH}=8)$. If the washing step was carried out with basic or acidic water/methanol mixtures it resulted in decreasing in analyte recovery, while other kinds of washing solutions (water alone, different kinds of buffers) prevented the satisfactory purification of the samples. The best results were obtained when washing the cartridge with $2 \mathrm{~mL}$ methanol. With regard to the elution step, water or acidic methanol/water mixtures did not give satisfactory results in terms of analyte recovery. On the contrary, $12 \mathrm{~mL}$ methanol gave good extraction yields, and this was chosen as the elution solution. The eluate was then dried under vacuum and re-dissolved in $2 \mathrm{~mL}$ methanol-water $(50+50, \mathrm{v} / \mathrm{v})$ for HPLC analysis.

Confirmation tests by HPLC-MS were used to determine whether or not peaks detected at the retention times of the analyte were in fact imazaquin. Imazaquin was identified by its retention time and the specific ion fragments $\left([\mathrm{M}+\mathrm{H}]^{+}\right.$at $\mathrm{m} / \mathrm{z} 312.3$ and $[\mathrm{M}+\mathrm{H}-\mathrm{COOH}]^{+}$at $\mathrm{m} / \mathrm{z}$ 267.1) in HPLC-MS according to the proposed conditions (Fig. 3).

Imazaquin Residue Levels in Soybeans Collected from Experimental Field

The developed method was applied to the analysis of 20 different soybeans samples collected from experimental field. No imazaquin residues $(\leq 0.005 \mathrm{ppm})$ were detected in soybeans at harvest time withholding period of 3 months after treatments of the pesticide. The maximum residue limits (MRLs) of imazaquin set by the US government for soybeans was $0.05 \mathrm{ppm}$ (Lin 2002) and no MRL of the pesticide set by Chinese legislation or Food and Agriculture Organization/World Health Organization yet. According to MRL set by USA, applying imazaquin in soybeans is safety.

The method developed for the determination of imazaquin residues in soybeans, based on HPLC with UV detection, has various advantages: high precision and accuracy, good selectivity, and feasibility. When compared to other methods found in the literature, the present method has the advantage of being inexpensive since it does not require expensive instrumentation and feasible since it does not need complicated sample pre-treatments or laborious analyte derivatization. The developed method was applied to the determination of imazaquin residues in soybeans grown in an experimental field following the recommended treatments.

\section{References}

Ahrens WH (1994) Weed Science Society of America. Herbicid handbook, 7th edn. Lawrence, KS

Anisuzzaman AKM, Amin M, Ogg N, Hoq F, Kanithi MR, Jenkins RE (2000) Synthesis of dimethyl derivatives of imidazolinone herbicides: their use in efficient gas chromatographic methods for the determination of these herbicides. J Agric Food Chem 48:5893-5902

Chen XY, Hu JY, Li JZ (2007) Determination of imazaquin residues in soil based on solid-phase extraction and high-performance liquid chromatography. J AOAC Int 90:568-574

Lanana A, Fago F, Marino A (1998) Simultaneous determination of imidazolinone herbicides from soil and natural waters using soil column extraction and off-line solid-phase extraction followed by liquid chromatography with UV detection or liquid chromatography/electrospray mass spectrometry. Anal Chem 70: 121-130 
Lin WX (2002) The compilation of residue limits standards for pesticides and veterinary drugs in foodstuffs in the world. Dalian Maritime University Press, Dalian

Nejad H, Safarpour MM, Cavalier T, Picard G, Souza M, Krynisky AJ, Chiu S, Miller P, Stout SJ (1998) Capillary electrophoresis determinative and LC-MS confirmatory method for screening selected imidazolinone herbicides from soil. J Capillary Electrophor 5:81-87

Nemoto S, Lehotay SJ (1998) Analysis of multiple herbicides in soybeans using pressurized liquid extraction and capillary electrophoresis. J Agric Food Chem 46:2190-2199
Steinheimer TR, Scoggin KD (1998) Estimation of imazethapyr in agricultural water by its cross-reactivity with either imazaquin or imazapyr ELISA kits. J Agric Food Chem 46:1883-1886

Stout SJ, Dacunha AR, Allardice DG (1996) Microwave-assisted extraction coupled with gas chromatography/electron capture negative ionization mass for simplified determination of imidazolinone in soil at the ppb level. Anal Chem 68: $653-658$

Wang XD, Liu XJ, Wang HL, Dong QX (2007) Utiliazation and degradation of imazaquin by a naturally occurring isolate of Arthrobacter crystallopoietes. Chemosphere 67:2156-2162 